\title{
A Magnetic Susceptibility Study of Spin-state Transitions in Rare-earth Trioxocobaltates(III)
}

\author{
By W. Hanumantharao Madhusudan, Krishnaswamy Jagannathan, Parthasarathy Ganguly, and C. N. \\ Ramachandra Rao," Solid State and Structural Chemistry Unit, Indian Institute of Science, Bangalore- \\ 560012, India
}

\begin{abstract}
Rare-earth trioxocobaltates(III), $\mathrm{Ln}\left[\mathrm{CoO}_{3}\right]$, with $\mathrm{Ln}=\mathrm{Pr}, \mathrm{Nd}, \mathrm{Tb}, \mathrm{Dy}$, and $\mathrm{Yb}$ exhibit low-spin to high-spin transitions of cobalt characterised by a maximum in the $\Delta \chi^{-1}$ against temperature plots where $\Delta \chi$ is the cobalt contribution to the magnetic susceptibility. The susceptibility behaviour is distinct from that of $\mathrm{La}^{2}\left[\mathrm{CoO}_{3}\right]$ which shows a plateau in the $\chi^{-1}-T$ curve accompanied by a structural transition. The temperature at which the $\Delta \chi^{-1}-T$ curve shows a maximum increases with the decrease in the size of the rare-earth ion. The susceptibility behaviour of solid solutions of $\mathrm{La}_{1-x} \mathrm{Nd}_{x} \mathrm{CoO}_{3}$ has been investigated to see how the behaviour characteristic of $\mathrm{Nd}\left[\mathrm{CoO} \mathrm{O}_{3}\right]$ changes to that of $\mathrm{La}\left[\mathrm{CoO}_{3}\right]$.
\end{abstract}

Transirions from the low-spin to the high-spin state of $d^{6}$ transition-metal ions are known to occur in transitionmetal complexes as well as oxides.,2 These transitions can be abrupt or gradual and are sometimes accompanied by structural changes. Spin-state transitions have been extensively investigated by magnetic susceptibility and Mössbauer experiments in the case of iron(II) complexes. Among the transition-metal oxides the rare-earth trioxocobaltates(III) of formula $\mathrm{Ln}\left[\mathrm{CoO}_{3}\right](\mathrm{Ln}=\mathrm{La}$ or rare earth) are so far the only solids known to exhibit such transitions..$^{2-4}$ Magnetic susceptibility and Mössbauer studies of $\mathrm{La}\left[\mathrm{CoO}_{3}\right]$ have shown that the cobalt ions in $\mathrm{La}\left[\mathrm{CoO}_{3}\right]$ are almost entirely in the low-spin state at low temperatures and transform to the high-spin state with increase in temperature..$^{5,6}$ In the $400-650 \mathrm{~K}$ region $\mathrm{La}\left[\mathrm{CoO}_{3}\right]$ exhibits a plateau in the $\chi^{-1}$ against $T$ plot due to short-range ordering of the low- and highspin ions. After the plateau region, there is long-range ordering of the two spin states accompanied by a change in the crystal symmetry. The exact shapes of the $\chi^{-1}$ against $T$ plots have not been worked out in the case of the rare-earth cobaltates where both the rare-earth and cobalt ions have magnetic moments. A recent study ${ }^{2}$ of the models for spin-state transitions in solids has shown that the nature of the $\chi^{-1}$ against $T$ plots varies with the mechanism of the transition, but unfortunately with the exception of $\mathrm{La}\left[\mathrm{CoO}_{3}\right]$, no other experimental data are available for verifying these models. We, therefore, considered it important to investigate the temperature variation of the contribution to the magnetic susceptibility of cobalt ions in a few rare-earth trioxocobaltates(III), $\mathrm{Ln}\left[\mathrm{CoO}_{3}\right](\mathrm{Ln}=$ rare earth), in order to characterise the spin-state transitions in these systems. For this purpose, we measured the susceptibilities of $\operatorname{Ln}\left[\mathrm{CoO}_{3}\right]$ compounds $(\mathrm{Ln}=\mathrm{Pr}, \mathrm{Nd}, \mathrm{Gd}, \mathrm{Tb}$, $\mathrm{Dy}, \mathrm{Ho}$, and $\mathrm{Yb}$ ) in the range $100-1000 \mathrm{~K}$ along with the corresponding aluminates, $\mathrm{Ln}\left[\mathrm{AlO}_{3}\right]$. From the difference in the susceptibilities of the corresponding cobaltates and aluminates, we have obtained the contribution of the cobalt ions to the susceptibility at different temperatures.

\section{EXPERIMENTAL}

All the materials were prepared using starting materials of better than $98.9 \%$ purity. Rare-earth trioxocobaltates-
(III) were prepared by the thermal decomposition of the corresponding cobalticyanides. ${ }^{7}$ This procedure gives essentially stoicheiomtric cobaltates as the only solid products. The rare-earth aluminates were prepared from a stoicheiometric mixture of the rare-earth and aluminium nitrates, precipitated as hydroxides using ammonia (except in the case of $\operatorname{Pr}\left[\mathrm{AlO}_{3}\right]$ ). These were decomposed at $1370 \mathrm{~K}$ in air with intermittent grinding. The compound $\operatorname{Pr}\left[\mathrm{AlO}_{3}\right]$ was prepared by heating a stoicheiometric mixture of $\mathrm{Pr}_{2} \mathrm{O}_{3}$ and $\mathrm{Al}_{2} \mathrm{O}_{3}$ in a vacuum. Solid solutions of $\mathrm{La}_{1-x} \mathrm{Nd}_{x} \mathrm{CoO}_{3}$ were prepared by taking a stoicheiometric mixture of $\mathrm{La}\left[\mathrm{CoO}_{3}\right]$ and $\mathrm{Nd}\left[\mathrm{CoO}_{3}\right]$, converting them into nitrates, and decomposing at $1070 \mathrm{~K}$. The product was repeatedly ground and sintered at $1120 \mathrm{~K}$. $X$-Ray diffraction patterns of $\mathrm{La}_{1-x} \mathrm{Nd}_{x} \mathrm{CoO}_{3}$ were recorded to ensure that the products were not mixtures, but true solid solutions. The crystal structure of the solid solution is identical to that of rhombohedral $\mathrm{La}\left[\mathrm{CoO}_{3}\right]$ when $x \leqslant 0.3$ and similar to that of tetragonal $\mathrm{Nd}\left[\mathrm{CoO}_{3}\right]$ when $x \geqslant \mathbf{0 . 6}$.

Magnetic susceptibility measurements were carried out in the $100-1000 \mathrm{~K}$ range by the Faraday method employing a Cahn RG electrobalance. The susceptibilities were independent of field strength and all measurements were made at $3000 \mathrm{G}\left(1 \mathrm{G}=10^{-4} \mathrm{~T}\right)$. The instrument was calibrated with $\mathrm{HgCo}(\mathrm{SCN})_{4}$. The values of $\chi_{M}$ are in c.g.s. units and the uncertainty in susceptibility measurements is $c a .0 .1 \% . \quad X$-Ray diffraction patterns were recorded with a Philips $X$-ray diffractometer.

\section{RESULTS AND DISCUSSION}

The values of $\mu_{\text {eff }}$ and $\theta$ of $\operatorname{Ln}\left[\mathrm{CoO}_{3}\right]$ and $\operatorname{Ln}\left[\mathrm{AlO}_{3}\right]$ compounds obtained from our susceptibility data are

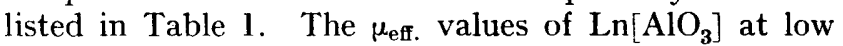
temperatures are close to those expected for the $\mathrm{Ln}^{3+}$ ions; deviations are, however, seen at high temperatures. In view of this we have obtained the contribution of $\mathrm{Co}^{3+}$ ions to the susceptibility, $\Delta x$, by point to point subtraction of the susceptibility of $\operatorname{Ln}\left[\mathrm{AlO}_{3}\right]$ from that of $\mathrm{Ln}\left[\mathrm{CoO}_{3}\right]$. We have plotted the inverse of this difference between the magnetic susceptibilities of $\mathrm{Pr}, \mathrm{Nd}$, $\mathrm{Tb}, \mathrm{Dy}$, and $\mathrm{Yb}$ cobaltates and the respective aluminates, $\Delta \chi_{M}{ }^{-1}$, against temperature in Figure 1 . In principle, this difference should directly give the contribution to susceptibility from the cobalt ions, although such a subtraction procedure would involve greater uncertainties when the rare-earth ions have high magnetic moments as in $\mathrm{Gd}\left[\mathrm{CoO}_{3}\right]$ or $\mathrm{Ho}\left[\mathrm{CoO}_{3}\right]$. The shapes 
of the $\Delta x^{-1}-T$ plots of $\mathrm{Pr}, \mathrm{Nd}, \mathrm{Tb}$, and Dy cobaltates are distinctly different from the $\chi^{-1}-T$ plot of $\mathrm{La}\left[\mathrm{CoO}_{3}\right]$. Unlike $\mathrm{La}\left[\mathrm{CoO}_{3}\right]$ which shows a plateau in the $\chi^{-1}-T$ curve (in the $450-600 \mathrm{~K}$ region), the former cobaltates show promiment maxima in the $\Delta \gamma^{-1}-T$ curves. In Figure 2 we have plotted the $\mu_{\text {eff. }}(\mathrm{Co})$ values of these cobaltates against temperature, the $\mu_{\text {eff. }}$ values being calculated from the $\Delta y$ values assuming that the Curie law holds. We see that $\mu_{\text {effir }}(\mathrm{Co})$ of the cobaltates is essentially constant at low temperatures and shows a marked increase around a temperature corresponding to the maximum in the $\Delta \chi^{-1}-T$ curve (Figure 1).

Magnetic susceptibilities of $\mathrm{Gd}\left[\mathrm{CoO}_{3}\right]$ and $\mathrm{Ho}\left[\mathrm{CoO}_{3}\right]$

TABLE 1

Magnetic moments, $\mu_{\text {eff., }}$ and $\theta$ values of $\mathrm{Ln}\left[\mathrm{CoO}_{3}\right]$ and $\mathrm{Ln}\left[\mathrm{AlO}_{3}\right]^{n}$

\begin{tabular}{|c|c|c|c|c|}
\hline Compound & $\begin{array}{l}\text { Temperature } \\
\text { range/K }\end{array}$ & 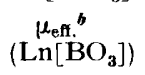 & $\begin{array}{c}\theta / K \\
\left(\operatorname{Ln}\left[\mathrm{BO}_{3}\right]\right)\end{array}$ & $\begin{array}{c}\mu_{\text {eff. }}\left(\mathrm{Ln}^{\mathrm{a}+}\right){ }^{\mathrm{e}} \\
\text { theoretical }\end{array}$ \\
\hline \multirow[t]{2}{*}{$\operatorname{Pr}\left[\mathrm{CoO}_{3}\right]$} & $<190$ & 3.73 & 35 & \\
\hline & $>700$ & 6.36 & 524 & \\
\hline \multirow[t]{2}{*}{$\operatorname{Pr}\left[\mathrm{AlO}_{3}\right]$} & $<325$ & 3.58 & 53 & 3.58 \\
\hline & $>325$ & 3.75 & 90 & \\
\hline $\mathrm{Nd}\left[\mathrm{CoO}_{3}\right]$ & $<\mathbf{2 5 0}$ & 3.71 & 51 & \\
\hline \multirow{3}{*}{$\mathrm{Nd}\left[\mathrm{AlO}_{3}\right]$} & $<325$ & 3.58 & 67 & 3.62 \\
\hline & $325-550$ & 3.87 & 132 & \\
\hline & $>550$ & 4.14 & 237 & \\
\hline \multirow{2}{*}{$\mathrm{Gd}\left[\mathrm{CoO}_{3}\right]$} & $<370$ & 7.80 & 3 & \\
\hline & $370-500$ & 8.56 & 70 & \\
\hline \multirow{2}{*}{$\mathrm{Gd}\left[\mathrm{AlO}_{3}\right]$} & $<370$ & 7.78 & 4 & 7.94 \\
\hline & $370-500$ & 8.52 & 62 & \\
\hline \multirow[t]{3}{*}{$\mathrm{Tb}\left[\mathrm{CoO}_{3}\right]$} & $<\mathbf{3 5 0}$ & 10.38 & 2 & \\
\hline & $350-675$ & 11.03 & 48 & \\
\hline & $>675$ & 12.52 & 245 & \\
\hline \multirow{3}{*}{$\mathrm{Tb}\left[\mathrm{AlO}_{3}\right]$} & $<350$ & 10.20 & 2 & 9.72 \\
\hline & $350-625$ & 10.76 & 40 & \\
\hline & $>625$ & 11.10 & 82 & \\
\hline \multirow[t]{3}{*}{$\mathrm{Dy}\left[\mathrm{CoO}_{3}\right]$} & $<365$ & 10.41 & 3 & \\
\hline & $365-625$ & 11.02 & 47 & \\
\hline & $>645$ & 12.53 & 245 & \\
\hline \multirow[t]{3}{*}{$\operatorname{Dy}\left[\mathrm{AlO}_{3}\right]$} & $<310$ & 10.18 & 1 & 10.63 \\
\hline & $310-603$ & 10.76 & 40 & \\
\hline & $>625$ & 11.08 & 79 & \\
\hline \multirow[t]{3}{*}{$\mathrm{Ho}\left[\mathrm{CoO}_{3}\right]$} & $<325$ & 10.58 & 4 & \\
\hline & $350-650$ & 11.25 & 45 & \\
\hline & $>650$ & 12.33 & 176 & \\
\hline \multirow{3}{*}{$\mathrm{Ho}\left[\mathrm{AlO}_{3}\right]$} & $<325$ & 10.57 & 4 & 10.6 \\
\hline & $350-650$ & 11.26 & 44 & \\
\hline & $>650$ & 11.75 & 109 & \\
\hline \multirow{2}{*}{$\mathrm{Yb}\left[\mathrm{CoO}_{3}\right]$} & $<375$ & 5.38 & 77 & \\
\hline & $375-850$ & 5.67 & 107 & \\
\hline \multirow{2}{*}{$\mathrm{Yb}\left[\mathrm{AlO}_{3}\right]$} & $<700$ & 4.69 & 99 & 4.54 \\
\hline & $>700$ & 4.50 & 37 & \\
\hline
\end{tabular}

" $\mu_{\text {enf. }}\left(\operatorname{Ln}\left[\mathrm{BO}_{3}\right]\right)$, where $\mathrm{B}=$ Co or $\mathrm{Al}$, and $\theta\left(\mathrm{Ln}\left[\mathrm{BO} \mathrm{O}_{3}\right]\right)$ were obtained from least-squares fit of the susceptibility data to a Curie-Weiss law. ${ }^{b}$ Units are Bohr magneton, $\mu_{B}-0.927 \times$ $10^{-23} \mathrm{~A} \mathrm{~m}^{2}$. ${ }^{c}$ Calculated from the equation $\mu_{\mathrm{eff}}=g \sqrt{J(J+1) \mu_{\mathrm{B}}}$.

are very close (within $0.5 \%$ ) to those of the corresponding aluminates, $\mathrm{Gd}\left[\mathrm{AlO}_{3}\right]$ and $\mathrm{Ho}\left[\mathrm{AlO}_{3}\right]$, up to relatively high temperatures suggesting that most of the cobalt ions are in the diamagnetic low-spin state in these two cobaltates up to these temperatures (Figure 3). Deviation from the Curie-Weiss law found at low temperatures $(c a .500 \mathrm{~K})$ in these compounds seem to be entirely ascribable to the rare-earth ion. The interpretation of the suceptibility of $\mathrm{Gd}\left[\mathrm{CoO}_{3}\right]$ below $500 \mathrm{~K}$ by Casalot et al. ${ }^{8}$ in terms of high-spin $\mathrm{Co}^{3+}$ ions appears to be in doubt since both $\mathrm{Gd}\left[\mathrm{CoO}_{3}\right]$ and $\mathrm{Gd}\left[\mathrm{AlO}_{3}\right]$ show identical susceptibility behaviour.

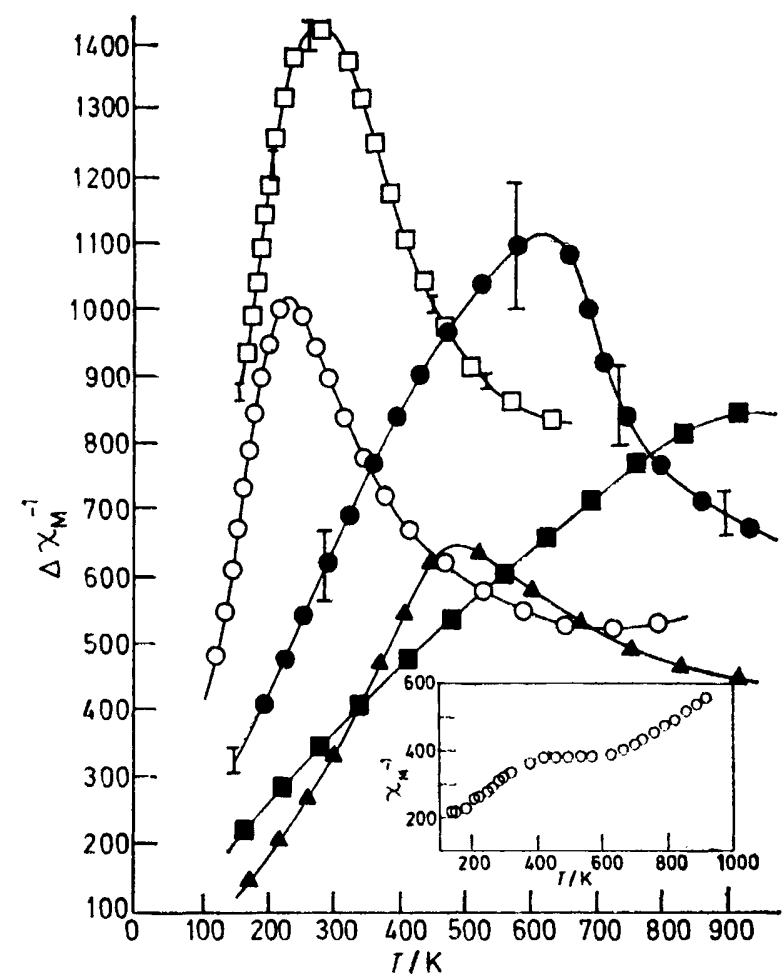

Figure 1 Plots of cobalt contribution to the inverse susceptibility against temperature in $\operatorname{Pr}(\mathrm{O}), \mathrm{Nd}(\square), \mathrm{Tb}(\mathbf{A})$, Dy (O), and $\mathrm{Yb}(\square)$ trioxocobaltates. $\Delta_{\chi}$ values are in c.g.s. units. Error bars on a few points are shown to indicate experimental uncertainties. The $\chi^{-1}-T$ curve of $\mathrm{La}\left[\mathrm{CoO}_{3}\right]$ is shown in the inset for comparison

From Figure 1 we see that the temperature corresponding to the maximum in the $\Delta y^{-1}-T$ curves, $T_{\mathrm{ms}}$, increases as the size of the rare-earth ion decreases. The same trend is seen in the temperature, $T \mu$, at which $\mu_{\text {eff. }}$ starts increasing significantly in the $\mu_{\text {eff. }}(\mathrm{Co})-T$ plots of Figure 2. The values of $T_{\mathrm{m} s}$ and $T_{\mu}$ are quite close to each other and both are listed in Table 2 . We can consider these temperatures to reflect the spin-state equilibria in the rare-earth cobaltates. We shall refer to these temperatures as spin-state transition temperatures (following Demazeau et al. ${ }^{9}$ ). In the case of Gd and Ho cobaltates where we could not obtain clear maxima in the $\Delta \chi^{-1}-T$ plots, we can take the tempera-

TABLE 2

Spin-state transition temperature $(\mathrm{K})$ of $\mathrm{Ln}\left[\mathrm{CoO}_{3}\right]$ compounds

\begin{tabular}{|c|c|c|}
\hline $\mathrm{I}, \mathrm{n}$ & from $\frac{T_{\text {nis }}}{\Delta \chi^{-1}-T \text { plots }}$ & $\begin{array}{c}T_{\hat{\ell}} \\
\text { from } \mu_{\text {eff }}(\mathrm{C}(s)- \\
T \text { plots }{ }^{a}\end{array}$ \\
\hline La & $100^{b}$ & \\
\hline $\mathrm{Pr}$ & 220 & 200 \\
\hline $\mathrm{Nd}$ & 285 & 240 \\
\hline $\mathrm{Gd}$ & 500 " & \\
\hline $\mathrm{Tb}$ & 490 & 430 \\
\hline Dy & 590 & 590 \\
\hline Ho & $650^{\circ}$ & \\
\hline Yb & 860 & 830 \\
\hline
\end{tabular}

a Temperature around which $\mu_{\mathrm{en}}$.(Co) shows a marked increase from the nearly constant value in Figure 2 . 'b From ref. 4. Temperature at which $\mathrm{Ln}\left[\mathrm{CoO}_{3}\right]$ shows deviation in susceptibility from that of $\mathrm{Ln}\left[\mathrm{AlO}_{3}\right]$. 
tures at which $\chi^{-1}$ of the cobaltate differs from that of the aluminates (Figure 3) to be close to the spin-state transition temperatures; these temperatures do indeed fit in nicely with the other data (Table 2). The trend in spin-state transition temperatures found here also finds support from the susceptibility measurements of Demazeau et al. ${ }^{9}$ on $\mathrm{Y}\left[\mathrm{CoO}_{3}\right]$ and $\mathrm{Lu}\left[\mathrm{CoO}_{3}\right]$ (prepared under high oxygen pressures) and of Kappatsch et al. ${ }^{10}$ on

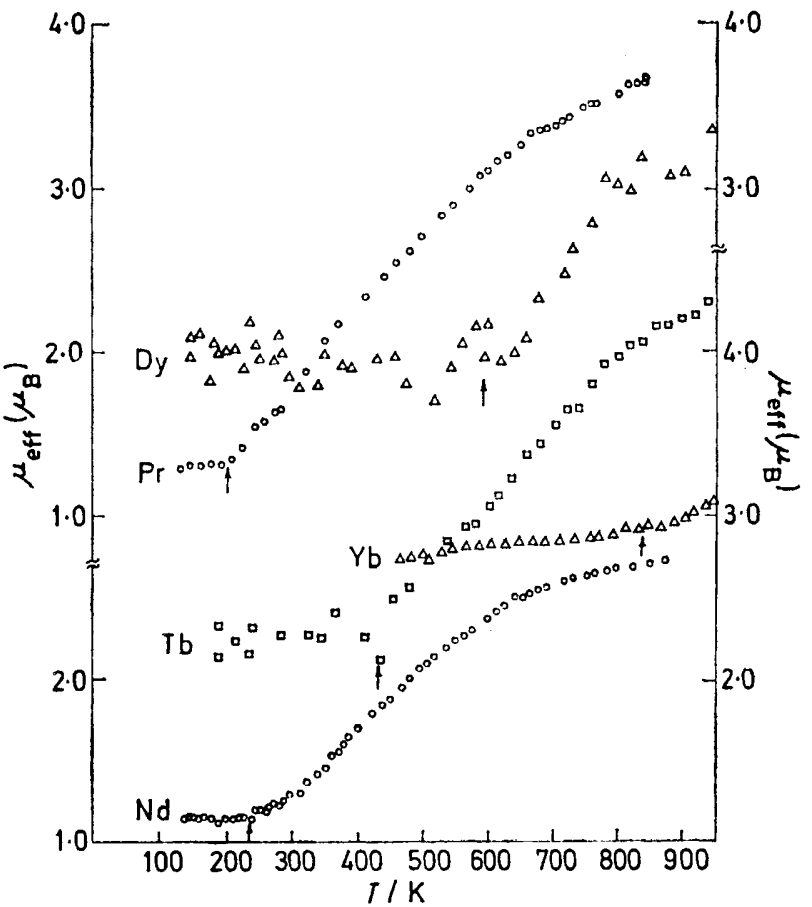

FIGURE 2 Plot of $\mu_{\mathrm{eff}}\left(\mathrm{Co}^{3+}\right)$ in $\mathrm{Ln}\left[\mathrm{CoO}_{3}\right]$ against temperature. Arrows indicate $T_{\mu}$ values

$\mathrm{Y}\left[\mathrm{CoO}_{3}\right]$. The $\chi^{-1}-T$ curves of these workers are similar to those of the $\Delta \chi^{-1}-T$ plots shown in Figure 1. The transition temperatures of Demazeau et al. ${ }^{9}$ vary in the order $\mathrm{Gd}<\mathrm{Y}<\mathrm{Lu}$. The actual values of the transition temperatures found by us are generally higher, possibly due to the presence of slight non-stoicheiometry in the samples.

It has been pointed out that the low-spin-high-spin equilibria in rare-earth cobaltates is governed by the relative magnitudes of exchange energy and crystalfield splitting, $\Delta_{\mathrm{cf}}$. It is possible that the polarization of the ligand orbitals (in the $\mathrm{CoO}_{6}$ octahedra) by the rareearth ions may significantly affect $\Delta_{\text {if: }}$. The increasing trend in the spin-state transition temperatures with the decreasing size of the rare-earth ion would suggest an increase in $\Delta_{\mathrm{cf}}$ as we go down the rare-earth series. This would be consistent with the known decrease in the unit-cell volume of the cobaltates with the decreasing size of the rare-earth ion. ${ }^{10}$ It can also be argued that $\Delta_{\text {cf }}$ should increase as we go down the rare-earth series because the $\pi^{*}$ orbital gets significantly stabilised as we go from $\mathrm{La}$ to $\mathrm{Lu}$ as suggested by Demazeau et al.$^{9}$ It is possible that other factors may also contribute to the observed trend in the spin-state transition temperatures.
In the dynamic model of Ramasesha et al..$^{2}$ the difference in the low-spin and high-spin population is determined by a coupling constant which determines the strength of coupling of an ion vs. cage mode to the spin states; during such a vibration the symmetry of the crystal field changes and the two spin states mix. It is possible that as we go down the rare-earth series, the value of the coupling constant changes. We must point out that the shapes of the $\Delta \chi^{-1}-T$ plots in the case of $\operatorname{Pr}, \mathrm{Nd}, \mathrm{Tb}$, and Dy cobaltates in Figure 1 suggest that the mechanism of the spin-state transitions is likely to be different from that in $\mathrm{La}\left[\mathrm{CoO}_{3}\right]$ which shows a plateau in the $\chi^{-1}-T$ curve accompanied by a structural transition..$^{\mathbf{5 , 6}}$ The shapes of the curves can be explained on the basis of the dynamic model of Ramasesha et al. ${ }^{2}$ referred to earlier.

We have found another example of spin-state transition in a cobalt oxide system where the above model seems to be applicable. This is the oxide $\mathrm{La}_{2} \mathrm{Co}_{0.5-}$ $\mathrm{Li}_{0.5} \mathrm{O}_{4}$ which was described some time ago by Blasse. ${ }^{11}$ This oxide is essentially diamagnetic up to $c a .300 \mathrm{~K}$; above this temperature, the population of the high-spin state increases progressively. The $\chi^{-1}-T$ plot of this oxide shows a maximum around $275 \mathrm{~K}$. The only difficulty with this system seems to be that there is

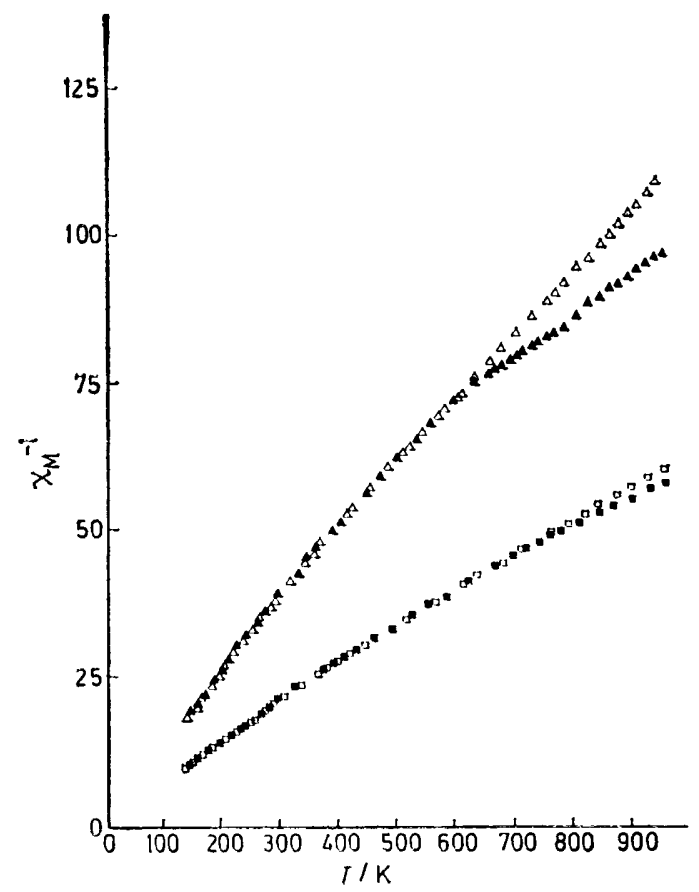

FIGURE 3 Inverse susceptibility against temperature plots for $\mathrm{Gd}$ and Ho trioxocobaltates and aluminates: $\mathrm{Gd}\left[\mathrm{AlO}_{3}\right](\triangle)$, $\mathrm{Gd}\left[\mathrm{CoO}_{3}\right](\Delta), \mathrm{Ho}\left[\mathrm{AlO}_{3}\right](\square), \mathrm{Ho}\left[\mathrm{CoO}_{3}\right]($

always a small poroportion of $\mathrm{Co}^{2+}$ which may also contribute to the observed shape of the $\chi^{-1}-T$ plot.

A comment on the nature of cobalt states in $\mathrm{Ln}\left[\mathrm{CoO}_{3}\right]$ compounds at temperature well beyond the maxima in the $\Delta \chi^{-1}-T$ curves would be pertinent. There is evidence to show that in this temperature range there may be charge transfer between high- and low-spin $\mathrm{Co}^{3+}$ producing $\mathrm{Co}^{2+}$ and $\mathrm{Co}^{4+}$ charge-transfer states. ${ }^{3-5}$ 
Such charge-transfer states are of importance in explaining the electron transport properties of the rare-earth cobaltates.

In order to find out whether there is a gradual vari-

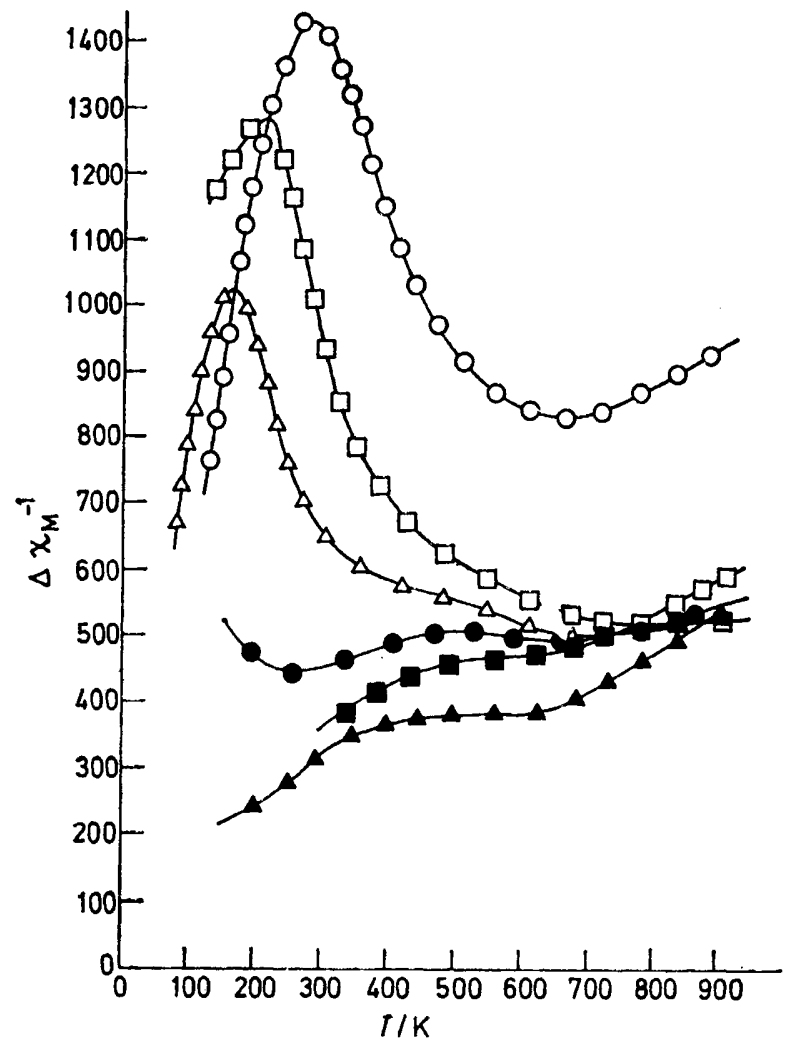

Figure 4 Temperature variation of the cobalt contribution to the inverse susceptibility of $\mathrm{La}_{1-x} \mathrm{Nd}_{x} \mathrm{CoO}_{3}: x=1(\mathrm{O})$, $x=0.8(\square), x=0.6(\triangle), x=0.3(0), x=0.1(\square), x=0$ ( $\Delta)$

ation in the spin-state transition temperature in a solid solution of two rare-earth cobaltates, we have investigated the susceptibility behaviour of the $\mathrm{La}_{1-x} \mathrm{Nd}_{x} \mathrm{CoO}_{3}$ system. In Figure 4 the contribution from the $\mathrm{Co}^{3+}$ ion to the magnetic susceptibility of the solid solutions is plotted against temperature. Figure 4 shows that the maximum in $\Delta \chi^{-1}-T$ plot (shown by $\mathrm{Nd}\left[\mathrm{CoO}_{3}\right]$ ) is seen in $\mathrm{La}_{1-x} \mathrm{Nd}_{x} \mathrm{CoO}_{3}$ solid solutions with $x \geqslant 0.6$. The temperature at which the maximum is seen progressively decreases with decrease in $x$, indicating that $\Delta_{\text {cf }}$ probably increases with increase in $x$ as expected. Solid solutions with $x \leqslant 0.3$ do not appear to show such maxima; the susceptibility behaviour of the composition with $x=0.1$ is in fact similar to that of $\mathrm{La}\left[\mathrm{CoO}_{3}\right]$ with a slight shift of the plateau region. It may be noted that compositions with $x \leqslant 0.3$ possess the rhombohedral structure of $\mathrm{La}\left[\mathrm{CoO}_{3}\right]$ while those with large $x(\geqslant 0.6)$ possess the $\mathrm{Nd}\left[\mathrm{CoO}_{3}\right]$ structure.

The authors thank the Department of Science and Technology, Government of India, for support of this research and Mr. N. Y. Vasanthacharya for assistance with the measurements.

[9/880 Received, 8th June, 1979]

\section{REFERENCES}

1 A. T. Casey and S. Mitra, in "Theory and Applications of Molecular Paramagnetism,' eds. E. A. Bourdreaux and L. N. Mulay, Wiley, New York, 1976.

${ }^{2}$ S. Ramasesha, T. V. Ramakrishnan, and C. N. R. Rao, J. Phys. $(C), 1979,12,1307$.

3 C. N. R. Rao and V. G. Bhide, 'Proceedings of the 19th Conference on Magnetism and Magnetic Materials,' American Institute of Physics, 1974, 504.

4 D. S. Rajoria, V. G. Bhide, G. Rama Rao, and C. N. R. Rao, J.C.S. Faraday $I I, 1974,512$. 932.

6 P. M. Raccah and J. B. Goodenough, Phys. Rev., 1967, 155,

B V. G. Bhide, D. S. Rajoria, G. Rama Rao, and C. N. R. Rao, Phys. Rev., 1972, B6, 1021.

7 P. K. Gallagher, Mater. Res. Bull, 1968, 3, 225.

8 A. Casalot. P. Dougier, and P. Hagenmuller, J. Phys. and Chem. Solids, 1971, 32, 407.

G. Demazeau, M. Pouchard, and P. Hagenmuller, J. Solid State Chem., 1974, 8, 202; see also High Temp.-High Pressures, 1976, 8, 624 .

10 A. Kappatsch, S. Quezel-Ambrunaz, and J. Sivardiere, J. Phys., 1970, 81, 369 .

i1 G. Blasse, J. Appl. Phys., 1965, 36, 879. 